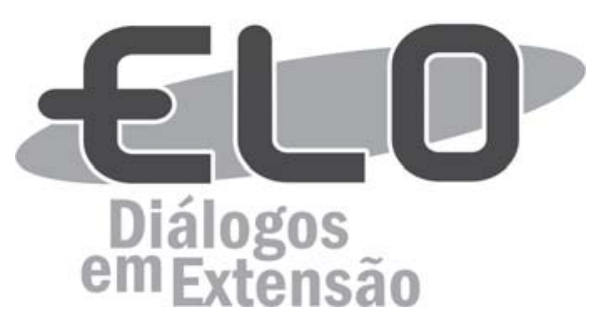

\title{
Fazer Extensão no semiárido: o caso do Campus Icó da UFCA
}

\author{
Wagner Pires da Silva1, Erlene Pereira Barbosa² e Jucieldo Ferreira Alexandre ${ }^{3}$
}

\begin{abstract}
Resumo: Com a expansão das universidades federais para o sertão nordestino, a população passou a ter acesso às ações de Ensino, Pesquisa e Extensão desenvolvidas por essas instituições. A Universidade Federal do Cariri-UFCA, criada em 2013, instalou um campus em Icó, cidade do interior cearense, distante $365 \mathrm{~km}$ de Fortaleza e $150 \mathrm{~km}$ da sede da Universidade, com a clara intenção de dialogar com a comunidade sertaneja. O curso de história ofertado pela UFCA na cidade, uma das mais antigas do Ceará, mediado pelo curso de extensão Entre as Páginas da História do Icó, procura, por meio dos registros históricos da cidade, dialogar com a população, procurando entender o passado do município e, assim, valorizar e proteger seu patrimônio histórico e cultural, representado pelo sítio urbano tombado pelo IPHAN. Este trabalho procura apresentar, pelo estudo de caso de um dos projetos de extensão, como a unidade acadêmica em implantação em Icó busca inserir-se na realidade da sociedade.
\end{abstract}

Palavras-chave: História. Semiárido. Universidade.

Área Temática: Educação. Territorialidade.

\section{Making Extension in the semiarid: the case of Campus Icó of UFCA}

Abstract: With the expansion of federal universities to the northeastern hinterland, the population began to have access to the actions of Teaching, Research and Extension developed by these institutions. The Federal University of Cariri - UFCA, created in 2013, installed a campus in Icó, a city in the interior of Ceará, far 365 $\mathrm{km}$ from Fortaleza and $150 \mathrm{~km}$ from the University headquarters, with the clear intention of dialoguing with the backwoods community. The history course offered by UFCA in the city, one of the oldest in Ceara, through the extension course Among the Pages of History of Icó, seeks, through the historical records of the city, to dialogue with the population, trying to understand the past of the municipality and thus, enhance and protect its historical and cultural heritage, represented by the urban site listed by IPHAN. This paper seeks to present through the case study of one of the extension projects, as the academic unit in implantation in Icó is seeking to insert itself in the reality of society.

Keywords: History. Semiarid. University.

\section{Extensión en el semiárido: el caso del Campus Icó de la UFCA}

Resumen: Con la expansión de las universidades federales al sertão nordestino, la población pasó a tener acceso a las acciones de Enseñanza, Investigación y Extensión desarrolladas por esas instituciones. La Universidad Federal del Cariri - UFCA, creada en 2013, instaló un campus en Icó, ciudad del interior cearense distante a $365 \mathrm{~km}$ de Fortaleza y distante $150 \mathrm{~km}$ de la sede de la Universidad, con la clara intención de dialogar con la comunidad sertaneja. El curso de historia ofrecido por la UFCA en la ciudad, una de las más antiguas de Ceará, a través del curso de extensión Entre las Páginas de la Historia del Icó, busca, a través de

\footnotetext{
${ }^{1}$ Administrador da UFCA. Mestre em Políticas Públicas e Gestão da Educação Superior pela UFC. Endereço: R. 17, n 140, José Walter, Fortaleza-CE. E-mail: wagner.pires@ufca.edu.br

${ }^{2}$ Graduanda em Ciências Sociais na UFC. Endereço: R. 17, n 140, José Walter, Fortaleza-CE. E-mail: erlene2013@gmail.com

${ }^{3}$ Pofessor Assistente do curso de História da Universidade Federal do Cariri e diretor do Instituto de Estudos do Semiárido (IESA), em Icó-CE. Av. Ten. Rocha, S/

N, Cidade Universitária, Juazeiro do Norte-CE. Email: jucieldo.alexandre@ufca.edu.br (Orientador).
} 
los registros históricos de la ciudad, dialogar con la población, buscando entender el pasado del municipio y así valorar y proteger su patrimonio histórico y cultural, representado por el sitio urbano tumbado por el IPHAN. Este trabajo busca presentar por medio del estudio de caso de uno de los proyectos de extensión, como la unidad académica en implantación en Icó está buscando insertarse en la realidad de la sociedad.

Palabras clave: Historia. Semárido. Universidad.

\section{Introdução}

A Universidade Federal do Cariri realiza diversas atividades de extensão em seus Campi. Professores, técnicos e discentes realizam atividades de extensão, nas quais interagem com a sociedade externa, uma vez que, como observa uma das professoras do campus, em Icó:

A extensão deve, também, realizar o resgate da cidadania, realizar o empoderamento da comunidade, realizando o diálogo, o que pode ser feito não só por cursos, mas com auxílio técnico, suscitando debates de interesses da sociedade, estimulando a interação entre a universidade e seu entorno (POLIANA, 2016).

De acordo com Silva (2016) a unidade acadêmica sediada em Icó, o Instituto de Estudos do Semiárido - IESA oferece apenas um curso, o Bacharelado em História, e conta com 06 (seis) professores, 04 (quatro) servidores técnicos administrativos e 62 (sessenta e dois) alunos ativos de graduação.

Boa parte das ações de extensão no Campus tem a finalidade de aproximar a universidade das escolas de ensino médio da região, divulgando a instituição e o curso entre os estudantes que ingressarão nos cursos futuramente sediados no Campus.

A extensão deve privilegiar o debate com a comunidade para que essa se torne mais ativa na relação com a universidade, realizando uma troca de saberes e não uma simples recepção do conhecimento. É como diz um dos extensionistas:

... o aprendizado do aluno ele tá para além da sala de aula... esses projetos vieram para enriquecer o conhecimento do aluno... possibilita contatos diretos com a comunidade, né com as pessoas que moram na cidade e é uma troca de experiência aluno mais instituição, instituição mais população (LUCAS, 2016).

As atividades de extensão do IESA buscam o contato com a sociedade e, também, buscam tirar desse contato uma nova relação capaz de transformar a universidade e a sociedade.

\section{Objetivos}

Este trabalho procura apresentar como um dos projetos de extensão realizados pela UFCA em Icó pode dialogar com a história do território, e apontar como a educação superior pode contribuir para que a cidade possa conscientizar-se em relação a preservação do patrimônio histórico da região, dentro de uma perspectiva de partilha de saberes entre universidade e comunidade.

\section{Uma universidade Sertaneja}

O Campus em Icó foi instalado em 2014, abrigando o Instituto de Estudos do Semiárido - IESA e, tem como principal objetivo a construção, a partir das ações de ensino, pesquisa, extensão e cultura, de conhecimentos úteis à convivência sustentável do homem com o território do Semiárido nordestino. Baseia-se na valorização das potencialidades socioeconômicas e ambientais da região, buscando contribuir para a mudança da realidade da região por meio das ações próprias do fazer universitário (IESA, 2015).

Inicialmente, a unidade acadêmica recebeu o curso de História com ênfase em Gestão de Patrimônio Histórico e Cultural e Patrimônio socioambiental. Esse primeiro curso foi pensado para a cidade, levando em conta o sítio histórico tombado, o que permitiria um diálogo inicial com a comunidade sobre a preservação de seu Patrimônio histórico.

A universidade não pode vir ao semiárido apenas para replicar um conhecimento produzido em outros lugares, ela deve se reinventar, não apenas repassar, precisa apreender e assim transformar a 
vida sertaneja, se transformando junto, como observado por uma das graduandas do campus Icó, para quem a educação deve

... fazer com que as pessoas tivessem acesso a um conhecimento, mas que esse conhecimento não fosse simplesmente repassado pra elas, fosse construído junto com elas, como Freire mesmo falou, eu acho que na Pedagogia do Oprimido, que nós temos que construir uma pedagogia não do opressor para o oprimido e não de cima para baixo e sim uma pedagogia pensada pelo oprimido para o oprimido para que ele possa sair desse quadro de opressão (Karina, 2016).

Uma vez que o Campus Icó da UFCA pretende ser identificado como uma universidade sertaneja, aberta ao diálogo com a população do território em que está implantado, é na análise do fazer extensionista do campus que indica essa postura, o que pode ser observado na tentativa de mediação entre os saberes acadêmicos e os saberes populares.

\section{Metodologia}

Um dos projetos de extensão realizados no Campus de Icó durante o ano de 2015 foi o Entre as Páginas da História do Icó: Oficinas sobre Fontes Históricas e Educação Patrimonial. O objetivo do projeto é perceber o patrimônio dentro da nova concepção, em que se possa superar a visão de patrimônio apenas como propriedades imobiliárias. Por isso pensou-se em trabalhar com os documentos do arquivo público de Icó, uma das cidades mais antigas do Ceará, a qual precisa, no entanto, passar por todo um processo de valorização de seu patrimônio e história, o que demanda o conhecimento sobre esses aspectos.

O projeto oferece oficinas de curta duração sobre fontes históricas, sua importância no trabalho do professor/historiador e sua valorização enquanto patrimônio documental. O público-alvo são os alunos do Ensino Médio de Icó. O projeto está embasado na premissa básica da Educação Patrimonial que considera a preservação dos bens culturais como uma prática social, que deve estar inserida no cotidiano das pessoas e promover relações sensíveis das comunidades com seu passado, memória e patrimônio. O foco deste trabalho se deu sobre esse projeto e os alunos envolvidos nele. Foi realizada durante o ano de 2016, uma oficina mensal, contando com a participação de cerca de 300 alunos da rede municipal de ensino.

\section{Resultados e discussões}

Em 1988, o IPHAN realizou o tombamento do conjunto urbanístico e arquitetônico da Cidade de Icó, constituído pelo perímetro urbano, traçado pela metrópole portuguesa no século XVII,

Esse sítio tombado é visto como um dos pontos positivos da cidade, tanto pela beleza quanto pelo valor histórico e pela possibilidade de ser utilizado pelo curso em suas atividades, como pode ser observado na fala de uma das extensionistas:

... eu acho Icó a coisa mais linda, assim, ali o Largo eu acho lindo, tem, tem estrutura ali, que eu fico analisando qual o mais bonito, tem o teatro e a cadeia que eu acho particularmente lindo e quanto a isso de movimentação, de morar aqui, eu acho bom, uma cidade tranquila, claro que tem algumas dificuldades que qualquer outra cidade tem, tanto pequena, quanto grande, mas eu gosto de morar aqui... (Vitória, 2016)

Questionando os dois alunos ligados diretamente ao projeto, como bolsistas, perguntou-se o que é extensão, ambos responderam não com um conceito, mas apontam para a finalidade de contato, de ponte entre o que é produzido na universidade e a comunidade, que envolve trocas e que vai além da sala de aula.

Extensão... é aquilo, fazer com que a universidade seja uma universidade para além de seus muros, fazer com que haja uma interação entre a comunidade acadêmica e a comunidade local, é fazer com que aquilo, o conhecimento produzido dentro da universidade possa ir além dela e possa se tornar ações de intervenção na própria comunidade. (Sophia, bolsista de extensão) 
O fato de a cidade ser tombada pelo patrimônio histórico é um assunto controverso e são muitos os moradores da cidade que não valorizam esse patrimônio. Para os extensionistas, a extensão, por meio de suas atividades pode trabalhar junto a população para desconstruir essa rejeição:

...gerar a interação universidade/sociedade, gerando conhecimento pra aquele pessoal e eu acredito que consequentemente, os projetos de extensão que a gente vai abordar aqui, no Icó vão mudar essa visão que as pessoas têm hoje de desvalorizar o patrimônio histórico que ela tem. (Felipe bolsista de extensão)

O estímulo para buscar novos conhecimentos também foi percebido pelos estudantes. Uma delas ao explicar o que entendia por extensão, exemplificou esse despertar do desejo de ampliação, por meio da extensão, do que já estava aprendendo:

Assim, extensão, pra mim, eu acho que é estender o conhecimento e o que eu poderia levar desses projetos foi, porque, assim, eu fiquei apaixonada por cinema brasileiro, é tanto que participei de uma oficina de uma pessoal de, é... acho que era, acho não, era de Fortaleza, que tava no Cariri que eles rodam com cinema, cinema itinerante, eu participei de uma oficina, ganhei até um certificado, pra, é... saber como se trabalhar com cinema, projetar e também como fazer projetos e eu acho muito importante porque cada um tem uma especificidade.. como é que eu posso dizer, tem o âmbito específico. (Sophia)

Ao serem perguntados sobre o que é extensão universitária, alguns não se detiveram na definição e chegaram a dar exemplos do que faziam os projetos de extensão, como forma de fazer entender o que compreendiam como extensão.

Extensão, como a palavra já disse é algo que se estende, é algo que vai além, então numa universidade, extensão, algo que vai além é quando sai da sala de aula, sai daquela coisa monótona de um professor estar falando com o aluno e o aluno passa a agir na sociedade, tipo a ação de extensão dos alunos que estavam construindo uma ponte entre os icoenses e a sua própria história, como no projeto que eu faço parte que conecta a cidade com o patrimônio histórico e o projeto também viabiliza a questão da ponte entre as pessoas e o próprio patrimônio, então a extensão é uma forma que você sai, de uma forma bem prática, é a saída de alunos das salas de aula à sociedade para agir no meio da sociedade. (Felipe)

Fica claro nos depoimentos a busca de contato com a sociedade icoense, a tentativa de compartilhar saberes com o popular e o desejo de estender a atuação dos projetos às comunidades rurais, aos estudantes de Ensino Médio, mencionando ainda agricultores, irrigantes, colonos de assentamento do MST, presidiários, e outros grupos percebidos pelos bolsistas no município.

(...) tem alguns que é do professor Jucieldo né, que é justamente pra transcrever, só não tô lembrada agora o nome da ação, mas é pra transcrever os dados dos documentos oficiais do século XVI, XVII que está ali no Câmara e cadeia, (Felipe)

Em seu relato sobre as atividades do projeto de extensão, a extensionista falou um pouco da participação nas oficinas realizadas no arquivo público de alunos do ensino médio das escolas da cidade:

... ele mexe com arquivos antigos da cidade, óbitos, registros de nascimento, sabe? E ele faz oficinas também, inclusive as últimas oficinas foram com o pessoal da Escola Profissional, que a gente assim, que a gente se sentou, uma comunidade dum grupo só, a gente trazia eles e mostrava como era o processo de, de mexer com arquivo, documento, pegar o arquivo, ter todo cuidado, porque, porque são folhas antigas, não podia se expor ao sol, tem que usar roupa específica, sabe? A leitura também é difícil porque era, eram outros tempos, enfim, era escrito a mão, enfim são os que eu conheço. (Sophia) 
As oficinas são ministradas pelos discentes que participam do projeto, com apoio do professor e dos técnicos ligados ao campus, no entanto a presença de outros estudantes é estimulada, como forma de ampliar as trocas de conhecimento e experiência. O envolvimento de outros alunos do curso popularizou as atividades, fazendo com que os outros discentes do campus, embora não soubessem o nome do projeto de extensão, admirassem o trabalho realizado pelos coordenadores do projeto e os bolsistas:

eu não lembro o título definido, mas eu lembro das ações. Uma ação de extensão era a que dois alunos, a Sofia e o Felipe, eles iam pra um acervo histórico aqui de Icó, na Casa de Câmara e cadeia, eles pesquisavam documentos antigos e realizavam atividade paleográfica. O que é isso? Eles pegavam um texto em escrita antiga e arcaica e traziam pra nossa língua, tornando mais acessível pras pessoas daqui, pra poder gerar um, como é, acessibilidade, aos documentos históricos pra que os icoenses soubessem da própria história, tavam sendo um intermédio entre as pessoas e a própria história. (Raquel, discente do curso de História da UFCA)

É interessante observar como os bolsistas assumem o protagonismo do programa, que longe de ser visto só como mais uma atividade curricular, é entendido como uma oportunidade de formação, o que pode ser observado por falas como a que segue abaixo:

eu estou trabalhando com um processo criminal agora ele é do final do século XIX, de 1854, se chama "assassinato de João Martins", e aí a gente se reúne com os professores, o coordenador e a vice coordenadora do nosso projeto, e aí a gente debate alguns textos e eles falam um pouco pra gente sobre essas fontes, como a gente poderia trabalhar, é... e depois a gente vai lá no arquivo e nós mesmos digitalizamos essa fonte, nós mesmos transcrevemos e montamos o nosso conteúdo que a gente vai trabalhar na oficina e a forma que a gente vai trabalhar na oficina $\mathrm{Eu}$, geralmente, trabalho na oficina lá quando eu vou trazer o projeto, o processo criminal, eu passo um slide pro pessoal explicando como se dá a importância do processo-crime como fonte, desde quando ele começou a ser trabalhado, a metodologia que se dá com os processos criminais e aí depois, eu passo, já no final da oficina, eu entrego pra eles um trecho numa folha com uma parte do processo criminal pra eles tentarem transcrever e ver realmente a importância de saber manusear esse tipo de fonte.. (Felipe)

A importância da construção coletiva é ressaltada como algo inerente à prática, como se observa no relato da Sophia sobre as atividades: "só era nós três no projeto, mas tinha pessoas da faculdade, nossos colegas de, enfim, se disponibilizava pra ir com a gente sabe", ela complementa: "a gente fazia, cada um, de tudo um pouco e tudo a mesma coisa, sabe? " Ela resume tudo:

(...) o mais importante que eu vejo é a construção do conhecimento, a gente tá construindo um conhecimento junto, a gente pode debater um com o outro o que tá acontecendo, o que pode fazer pra mudar, eu acho que o foco é esse a visão crítica que a gente tá querendo despertar nas pessoas.

Cada fala reflete o desejo de influenciar positivamente a comunidade em que estão inseridos. Felipe expressa, acerca dos naturais da cidade, que ele deseja que essas pessoas "possam ficar aqui interagindo na cidade delas, construindo conhecimentos para melhorar a forma como a comunidade local vive". Há uma compreensão de que devem dar retorno no investimento que a sociedade lhes proporciona quando cursam uma universidade pública.

(...) não somente pegar meu diploma aqui e pronto sou uma bacharel em história, bacharel em gestão pública, não, o que eu quero pra minha vida e no que ela pode interferir na vida das pessoas? Eu acredito que esse impacto já deve tá acontecendo, isso na vida dos nossos alunos e na família deles e as pessoas, os vizinhos vão vendo e vão se questionando e também vão querer que seus filhos, seus sobrinhos possam participar, possam ter acesso. (Sophia) 
Abrir caminhos e apontar uma direção seriam papéis da universidade percebidos pelos bolsistas, como afirma um deles: "eu acho que realmente uma universidade (...) teria que, de fato, oferecer caminhos, a universidade oferecer caminhos para aquela população se desenvolver". Os participantes desejam mostrar, por meio da extensão, o que a cidade de Icó pode realizar:

(...) a gente discutia como é que a gente poderia trazer a cidade a tona, como é que a gente podia fazer pra que a cidade se restabelecesse, pra poder ter um movimento turístico aqui... (Vitória, 2016)

Os estudantes, em alguns momentos, expressam claramente a convicção de que a universidade não pode ficar apenas dentro de seus muros e desejam ampliar o alcance das discussões das quais participam. O desejo de ser um agente de mudanças é externalizado em falas como esta:

Possibilitar que outras pessoas tivessem acesso a essas discussões, pudessem participar desses debates e conhecer um pouco mais sobre a cidade que eu vi, porque eu escolhi vir pra cá, então eu acredito que tenho por obrigação estar participando de tudo que possa intervir de forma positiva pra que a comunidade possa se emancipar intelectualmente desses cabrestos que a cercam. (Felipe)

As falas apontam para uma identificação entre ação e conhecimento, em que conhecer é fazer (MATURANA E VARELA, 2001). Uma universidade sertaneja, voltada para a convivência com o semiárido, deve fazer essa identificação e nortear por ela sua atuação. Daí a importância desse e de outros projetos de extensão realizados no campus: fazer a ponte entre universidade e comunidade.

\section{Conclusões}

Na verdade, o que está acontecendo, no campus, são diversas construções: construção de uma universidade; construção de profissionais; construção da sociedade; cada um construindo ao outro de forma compartilhada, afinal, ao mesmo tempo em que construímos o mundo somos construídos por ele (MATURANA E VARELA, 2001). É preciso, como aponta Morin (2013, p. 76-77) "perceber as ligações, interações e implicações mútuas, os fenômenos multidimensionais, as realidades que são simultaneamente, solidárias e conflituosas". Dessa forma essas construções simultâneas poderão dar sentido a um contexto mais amplo, um tecido social que demonstre que a universidade é diferente não só no discurso, mas em suas práticas. São atividades como as que foram descritas neste trabalho que evidenciam o fazer extensionista, ao promover não só diálogo entre a universidade e a comunidade, mas a produção de novos saberes.

Construir uma universidade sertaneja é criar uma cultura organizacional que leve em consideração a convivência com o semiárido, os saberes populares e busque estar mais próxima da comunidade extramuros, sabendo que essa postura é necessária para a construção de um conhecimento pertinente e socialmente inserido.

Por isso as ações de extensão são importantes. Cada projeto extensionista, realizado em Icó, realizou diálogos com a sociedade, os saberes populares e acadêmicos foram partilhados nesses encontros e permitiu a universidade ter contato com as necessidades da população, ao mesmo tempo em que a cidade tomou conhecimento das potencialidades da universidade para resolução de suas demandas. (SILVA, p. 123, 2016)

Os campi do interior e as novas universidades federais sediadas no sertão necessitam da dedicação dos seus servidores, técnicos e docentes, do movimento da juventude que compõe seu corpo discente e do apoio da sociedade para manter suas atividades, e mais, em um país em que imperam tantas desigualdades sociais e onde há falta de oportunidades educacionais, da presença do estado a garantir e financiar a sua existência, uma vez que, como diz Bauman (2013, p. 74), “a desigualdade de oportunidades educacionais só pode ser confrontada em ampla escala por políticas de Estado". 
A ascensão do governo Temer em 2016, que assumiu uma política de austeridade com corte nos investimentos na educação, levou a suspensão da implantação do Campus da UFCA em Icó, uma medida que não impediu a realização de suas atividades. Ensino, pesquisa e extensão continuam a ser realizados no IESA, a despeito das dificuldades, mostrando que a unidade, embora com tão pouco tempo de criação e já enfrentando a falta de recursos, o corte nos investimentos e outros tantos entraves em um momento de crise política, econômica e institucional, demonstra que, como registrou Euclides da Cunha: "O sertanejo é, antes de tudo, um forte".

\section{Referências}

BAUMAN, Zygmunt. Sobre educação e juventude. Trad. Carlos Alberto Medeiros. Rio de Janeiro: Zahar, 2013.

INSTITUTO DE ESTUDOS DO SEMIÁRIDO DA UNIVERSIDADE FEDERAL DO CARIRI (IESA/ UFCA). Relatório de Gestãodo Instituto de Estudos do Semiárido de 2014. Ano de publicação: 2015.

MATURANA, Humberto R.; VARELA, Francisco J. A árvore do conhecimento: as bases biológicas da compreensão humana. Trad. Humberto Mariotti e Lia Diskin. São Paulo: Palas Athena, 2001.

MORIN, Edgar. Educação e complexidade: os setes saberes e outros ensaios. Org. Maria da Conceição de Almeida e Edgard de Assis Carvalho. Trad. Edgard de Assis Carvalho. São Paulo: Cortez, 2013.

SILVA, Wagner Pires. As ações de extensão na construção de uma universidade sertaneja. 2016. 135f. Dissertação (Mestrado) - Universidade Federal do Ceará, Fortaleza, 2016.

Recebido para publicação em 19/3/2018 e aprovado em 25/9/2018. 